\author{
ADRIAN WESOŁOWSKI \\ https://orcid.org/0000-0002-2714-1749 \\ Uniwersytet Warszawski \\ Instytut Antropologii Społecznej Maxa Plancka \\ Halle an der Salle
}

\title{
TRZY HISTORIE O CELEBRYTACH*
}

\begin{abstract}
Abstrakt: Czy sława to wartościowy przedmiot badań historycznych, czy na zawsze pozostanie $\mathrm{w}$ domenie ekspertyzy specjalistów od marketingu? Historiografia sławy i celebrytyzmu, żywa w anglosaskim dyskursie akademickim, na próby odcięcia refleksji historycznej od problematyki sławy odpowiada stanowczym: nie! Poniższy tekst jest zbiorczą recenzją trzech prac dotykających wspomnianej problematyki, jakie ukazały się w ostatnim czasie. Recenzji towarzyszy również próba oceny, na ile dane prace reprezentują najsilniejsze prądy w dziedzinie.
\end{abstract}

Słowa kluczowe: sława, celebrytyzm, celebryta, historiografia, celebrity studies, Julia Fawcett, Antoine Lilti.
Abstract: Is fame a valuable problem for historiography, or will it always remain in the domain of marketing experts? The English celebrity history, well-developed in the West, would react with a fervent refusal to any attempts at considering fame being thought ahistorical. This article is a review of three current works pertaining to the problem. Additionally, it attempts to determine whether a Polish historian can use its contents as fair examples of the current trends in celebrity history.

Keywords: fame, celebrity, celebrities, historiography, celebrity studies, Julia Fawcett, Antoine Lilti.

Może być zaskoczeniem dla wielu badaczy, że sława i jej nowoczesna wersja, czyli celebrytyzm (celebrity), również mają swoją historię. Próba wyjaśnienia sensowności historiografii sławy spotyka się jednak z problemami na

* Na marginesie prac: Julia Fawcett, Spectacular Disappearances. Celebrity and Privacy, 1696-1801, Ann Arbor 2016, University of Michigan Press, ss. 280; Antoine Lilti, The Invention of Celebrity, 1750-1850, Cambridge 2017, Polity Press, ss. 320; Intimacy and Celebrity in Eighteenth-Century Literary Culture, red. Emrys D. Jones, Victoria Joule, Cham 2018, Palgrave Macmillan, ss. 304. 
trzech poziomach: po pierwsze, obronić trzeba istotność zjawiska, po drugie, zasadność jego badania, a po trzecie - wyjaśnić sensowność historyzacji celebrytyzmu.

$\mathrm{Na}$ gruncie polskiego dyskursu akademickiego kolejną przeszkodą jest bariera językowa. Podczas gdy angielskie słowo celebrity rozumiane jest jako mieszczące się w szerszym pojęciu sławy, fame, i jako takie funkcjonuje w języku angielskim od XVIII w. ${ }^{1}$, do języka polskiego słowa celebryta i celebrytka weszły dopiero na przełomie XX i XXI w. jako rzeczowniki osobowe, bez odniesienia do abstrakcyjnego konceptu (który tu nazywam celebrytyzmem). W rezultacie, obecne również na Zachodzie uprzedzenia wobec celebrytyzmu jako zjawiska płytkiego, pozbawionego głębszego znaczenia i w pewien sposób związanego z legendą upadku obyczajów w ponowoczesności ${ }^{2}$ są jeszcze bardziej wzmocnione, co skutkuje niemalże nieobecnością przedmiotu wśród zainteresowań polskich badaczy ${ }^{3}$.

Szeroko pojęty problem sławy nie został zupełnie przeoczony przez rodzimą naukę. Znalazł on częściowe opracowanie w studiach odnoszących się do „kultu jednostki” czy „bohatera narodowego”" Niewielkie zakorzenienie teoretyczne i głęboko wartościujący odbiór centralnego pojęcia często odróżniają badania nad wielkimi jednostkami od tych prowadzonych na Zachodzie. Podobnie, niegdyś głęboko rozwijany koncept „wzorca osobowego" 5 sprowadzony został do parasolowego pojęcia rozumianego głównie poprzez swobodne skojarzenie. Dlatego też przyjęcie konceptu sławy może być szczególnie ciekawe dla polskiego historyka, bowiem oferuje mu szansę na znalezienie platformy, na której omówić można zarówno celebrytyzm, jak i narodowy heroizm.

Różnice językowe, które przekładają się na odmienne tłumaczenia pojęć, są przyczyną jeszcze większego zdziwienia, jakiego bez wątpienia doświadczą czytelnicy dobrze znanych w Polsce pisarzy i filozofów, którzy podejmowali się refleksji na temat celebrytyzmu już od półmetka XX w. Daniel Boorstin ukuł niechętnie, ale nagminnie przytaczaną definicję celebrytów jako „ludzi

1 S. Tillyard, „Paths of glory”. Fame and the Public in Eighteenth-Century London, w: Joshua Reynolds. The Creation of Celebrity, red. M. Postle, London 2005, s. 61-69.

2 Patrz: Z. Bauman, Liquid Life, Cambridge 2005, s. 39-51.

${ }^{3}$ Wyjątkiem są tutaj prace z zakresu medioznawstwa, częściej o profilu stosowanym niż teoretycznym, chociaż patrz też: M. Molęda-Zdziech, Czas celebrytów. Mediatyzacja życia publicznego, Warszawa 2013. W ograniczonym zakresie, rozważania o sławie starałem się przenieść na grunt historyczny w A. Wesołowski, Nieśmiertelny $i$ dobroczynny. Historyczne badanie genezy i charakteru sławy Stanisława Staszica, KH 125, 2018, 1, s. 29-63.

${ }^{4}$ Istnieją dziesiątki ciekawych prac na ten temat, problematyczne są jednak próby weryfikacji kluczowych pojęć. Świetne ujęcie syntetyczne oferuje Magdalena Micińska, Między Królem Duchem a mieszczaninem. Obraz bohatera narodowego w piśmiennictwie polskim przełomu XIX i XX w. (1890-1914), Wrocław 1995.

${ }^{5}$ Znakomitością w tej mierze była Maria Ossowska. Patrz: M. Ossowska, Ethos rycerski i jego odmiany, Warszawa 1986. 
sławnych z tego, że są sławni”. Samo zjawisko było dla niego jedną z patologii (,pseudo-wydarzeń") dwudziestowiecznej kultury masowej ${ }^{6}$. Z kolei przedstawiciele szkoły frankfurckiej, na czele z Theodorem Adorno i Maxem Horkheimerem, widzieli w celebrytach postaci o tyle poważne, o ile niebezpieczne. „Sławne osobowości" były w ich opinii końcowym produktem przemysłu kulturowego, a ich zadaniem miało być wprowadzenie mas w stan uśpienia i bierności, dzięki czemu klasa dominująca mogła uniknąć niebezpieczeństwa rewolucji ${ }^{7}$. Edgar Morin jako pierwszy wskazał, że gwiazdy Hollywood pełnią w nowoczesnym społeczeństwie funkcję podobną do bohaterów mitologii ${ }^{8}$. Wkrótce okazało się, że celebrytyzm stanowi istotne, o ile nie fundamentalne zagadnienie społeczne jako dyskursywny wskaźnik treści, jedną z dominujących form zbiorowej reprezentacji, oraz podstawowy mechanizm rozpowszechniania popularnych wartości w nowoczesności. Ta konstatacja przyniosła pojawienie się wyspecjalizowanej refleksji teoretycznej. Chris Rojek w 2001 r. wyróżniał już różnorodne szkoły myślenia o celebrytyzmie, osadzone w tradycji subiektywistycznej, strukturalistycznej i poststrukturalistycznej ${ }^{9}$.

Dla wielu najlepszym dowodem stabilności dziedziny było powstanie w 2010 r. czasopisma naukowego "Celebrity Studies”. Od pierwszego numeru pojawiły się $\mathrm{w}$ nim wezwania do historyzowania tematu ${ }^{10}$ - zadania kontrowersyjnego, ponieważ pozornie ahistorycznego. Wkrótce okazało się jednak, że historycy nie mają znacznego problemu z podejmowaniem się tego zadania, przy zastrzeżeniu odpowiedniej definicji centralnego pojęcia i krytycznej operacjonalizacji badanych konceptów.

Historyczne badanie celebrytyzmu to tradycja osadzona w anglojęzycznej historiografii już od lat dziewięćdziesiątych XX w. Wyrosła ona w specyficznym kontekście akademickim. Na kwestię historyzacji sławy jako pierwszy uwagę zwrócił Leo Braudy w dziś już kultowej książce The Frenzy of Renown, opublikowanej w Stanach Zjednoczonych w 1986 r. ${ }^{11}$ Pobudzone w ten sposób zainteresowanie tematem zbiegło się $\mathrm{w}$ czasie $\mathrm{z}$ wydaniem prac kluczowych dla zagadnienia płci kulturowej ${ }^{12}$. W rezultacie, pierwsze studia celebrytyzmu, cofające się do XVIII i XIX w., skupiły swoją uwagę na tych historycznych aspektach sławy, które pomogły w emancypacji kobiet: na sławie aktorek, pisarek i filozofek, dzięki której udało im się przezwyciężyć hierarchię społeczną oraz zyskać

6 "A person who is well-known for his well-knownness”, D. Boorstin, The Image or What Happened to the American Dream, New York 1962, s. 57.

7 T. Adorno, M. Horkheimer, Dialektyka oświecenia, Warszawa 1994 (oryg. niem. 1947), s. 138-188.

${ }^{8}$ E. Morin, Les stars, Paris 1972.

${ }^{9}$ C. Rojek, Celebrity, New York 2001, s. 29-63.

10 J. Bennett, Historicising Celebrity Studies, „Celebrity Studies” 1, 2010, 3, s. 358-359; S. Morgan, Historicising Celebrity, „Celebrity Studies” 1, 2010, 3, s. 366-368.

${ }^{11}$ L. Braudy, The Frenzy of Renown. Fame and its History, Oxford 1986.

12 Przede wszystkim J. Butler, Gender Trouble. Feminism and the Subversion of Identity, New York 1991. 
niezależność finansową i znaczący głos w debacie publicznej ${ }^{13}$. Nieprzypadkowo takie studia zyskały popularność wśród tych historyków, którzy najszybciej zbudowali sojusze z akademicką teorią feministyczną, czyli wśród badaczy literatury i teatru. Od tego czasu historia celebrytyzmu rozkwitła. Dziś obejmuje ona tak różnorodne tematy, jak charakterystyka nowożytnych mediów, wczesne społeczności fanów, rosnąca zbiorowa fascynacja prywatnym życiem sławnych osób czy kreacja wizerunku we wczesnym oświeceniu. Obok celebrytek bada się sławę tancerzy, śpiewaków operowych i pisarzy, a przy okazji badania niesławy (notoriety) - rozgłos otaczający rabusiów i kryminalistów ${ }^{14}$.

Mimo tak szerokiego tematycznego rozstrzału, ścieżkami rozwoju tej dziedziny kierowała do tej pory dynamika ustalona w latach dziewięćdziesiątych, co nie tylko pomagało jej w rozwoju, ale również, do pewnego stopnia, było ograniczeniem. Trzy prace omówione poniżej pozwalają świetnie uchwycić szanse i wyzwania, przed którymi na tym etapie stoi historia celebrytyzmu.

\section{Celebryta jako performer}

Jako pierwszą wybrałem książkę Julii Fawcett z 2016 r., Spectacular Disappearances. Celebrity and Privacy, 1696-1801, poświęconą analizie autokreacji scenicznej i literackiej znanych aktorów na podstawie źródeł związanych ze sztukami teatralnymi (recenzji, opinii, scenariuszy) oraz autobiografii. Autorka, młoda badaczka związana z Wydziałem Teatru, Tańca i Performance'u prestiżowego Uniwersytetu Kalifornijskiego w Berkeley, rozpoczęła swój wywód pytaniem: ,jak nowoczesna jednostka może zachować kontrolę nad swoim wizerunkiem, podczas gdy wydaje się, że patrzy na nią cały świat?". Pytanie to, chociaż istotne dla każdego użytkownika mediów społecznościowych w XXI w., po raz pierwszy zostało zadane, jak przekonuje Fawcett, na scenie i ulicy porestauracyjnego oraz osiemnastowiecznego Londynu ${ }^{15}$. Co więcej, sposób, w jaki współcześni celebryci próbowali na nie odpowiedzieć, stanowił przejaw zwrotu w postrzeganiu relacji jednostek ze społeczeństwem. Pomiędzy aktorami i publicznością w Anglii na przełomie XVII i XVIII stulecia funkcjonowało nieznane wcześniej, nieuświadomione założenie dotyczące psychologicznej głębi

${ }^{13}$ Np. K. Straub, Sexual Suspects. Eighteenth-century Players and Sexual Ideology, Princeton 1992; C. Wanko, Roles of Authority. Thespian Biography in Eighteenth-century England, Lubbock 2003; Theatre and Celebrity in Britain 1660-2000, red. M. Luckhurst, J. Moody, New York 2005; F. Nussbaum, Rival Queens. Actresses, Performance, and the Eighteenth-century British Theater, Philadelphia 2010.

${ }^{14} \mathrm{~Np}$. P. Linebaugh, London Hanged. Crime and Civil Society in the Eighteenth Century, Cambridge 1992; A. McKenzie, The Real MacHeath, Social Satire, Appropriation, and 18th-century Criminal Biography, „Huntington Library Quarterly” 69, 2006, 4, s. 581-605.

15 „How can the modern individual maintain control over his or her self-representation when the whole world seems to be watching?", J. Fawcett, op. cit., s. 1 i 6. 
aktorów. Widzowie przychodzili do teatru z oczekiwaniem, że wykonawcy kultowych ról kryją w sobie unikalne "ja” i śledzili emocje przedstawiane na scenie, utożsamiając aktorów z często odgrywanymi rolami i przenosząc wykształcone $\mathrm{w}$ ten sposób przeświadczenia $\mathrm{z}$ teatru na życie codzienne ${ }^{16}$. Ten nowy sposób patrzenia na jednostkowość nie pojawił się przypadkiem właśnie w teatrze. Fawcett użyła pojęcia overexpression (nadekspresja, przerysowanie), żeby określić sposób performance'u, który opierał się na spektakularności przedstawienia swojej osobowości za pomocą zachowań, ubioru i rekwizytów w celu przekonania widza o tym, że „prawdziwa tożsamość wykonawcy roli [lub, używając pojęcia spolszczonego przez nauki o sztuce, performera - A.W.] będzie czytelna dla każdego, kto podjąłby się interpretacji" ${ }^{17}$. Mechanizm ten nie ograniczał się jednak do sceny i nie był sposobem odczytu postaci, ale kreacji osobowości, w efekcie czego sławni aktorzy ewokowali swoje role również podczas innych publicznych wypowiedzi. Struktura pracy Fawcett skupia się wokół rozdziałów poświęconych danej strategii używania nadekspresji, powiązanych z tymi strategiami rekwizytów (korony, dwóch peruk, książki i miniaturowego portretu) oraz celebrytów, używających danej strategii w życiu publicznym.

Spectacular Disappearances jest świetnym przykładem do omówienia m.in. dlatego, że jej najmocniejsze i najsłabsze strony są wyjątkowo charakterystyczne dla całej historiografii celebrytyzmu od lat dziewięćdziesiątych do dziś. Niewątpliwie oryginalny wkład pracy skupia się na tematyce wytyczonej przez dotychczasowe studia nad teatrem. Temat indywidualizmu przedstawionego w kategoriach wystąpienia, performance'u, relacji pomiędzy występującym a publicznością, znajduje tu świetne opracowanie, wyraźnie zakorzenione w literaturze teatrologicznej ${ }^{18}$. Centralny dla Fawcett mechanizm nadekspresji jest instynktownie rozpoznawalny w hiperbolizacji typowej również dla dwudziestowiecznych mass mediów. Pochwalić należy też zaznaczone przez Autorkę wystąpienie przeciw ortodoksji metodologicznej, każącej ograniczać się do jednolitego typu źródeł ${ }^{19}$. Fawcett wzięła pod uwagę różnorodne teksty kultury, również autobiografie, na które celebryci mogli rozciągać swoje strategie tworzenia wizerunku.

Biorąc jednak pod uwagę, iż tematyka sławy i celebrytyzmu jest znacznie szersza i w żaden sposób nie ograniczona do teatru, walka o uwzględnienie autobiografii w wykorzystanych typach źródeł wydaje się przejawem nadmiernej drobiazgowości. To wrażenie jest jeszcze bardziej wzmocnione, kiedy zdamy sobie sprawę, jak bardzo zagadnienie to zostało zdominowane przez

16 Ibidem, s. 1-3.

17 „An overexpressive performance secures the spectator's interest by seducing him or her into believing that the celebrity's true identity will be legible to anyone attempting to interpret it", ibidem, s. 4-5.

18 Ibidem, s. 9-12.

19 Ibidem, s. 7-8. 
historiografię teatru w ogóle ${ }^{20}$. Widząc szansę na przejęcie tematu przez historie teatru i kobiet, jedna z najważniejszych ekspertek, Laura Engel, zaproponowała utworzenie niezależnej dyscypliny pod nazwą actress studies ${ }^{21}$. Atmosfera tego rodzaju solipsyzmu narzuciła ograniczoną perspektywę również książce Fawcett. Nie dowiemy się z niej niczego o żadnym rodzaju gwiazd poza gwiazdami pióra i sceny teatralnej, np. o osobach związanych z ruchami politycznymi bądź religijnymi. Nawet wspomniani celebryci (Colley Cibber, Laurence Sterne, Alexander Pope, David Garrick, Mary Robinson) należą do najczęściej omawianych przez ostatnie dwie dekady ${ }^{22}$. Co więcej, chociaż od dawna dostrzega się, że celebrytyzm dotyczy procesów zachodzących pomiędzy trzema agentami - sławną osobą, pośrednikami w przekazie wizerunku i publicznością (tzw. celebrity-intermediaries-audience triad) ${ }^{23}$ - Fawcett opisuje wyłącznie punkt widzenia gwiazd i tylko im przypisuje sprawczość w budowaniu sławy, w tej kwestii również utrwalając podejście dominującego prądu w historiografii celebrytyzmu.

Książka Fawcett nie prowadzi do lepszego zdefiniowania granic zjawiska celebrytyzmu ani w historycznym kontekście, ani in abstracto. Autorka korzysta $\mathrm{z}$ funkcjonującego w literaturze przedmiotu konsensusu, który stanowi, iż celebrytyzm należy do dziedziny wiedzy milczącej: chociaż powszechnie wiadomo, czym jest, niezwykle trudno go zdefiniować. Panuje zgoda co do tego, że zjawisko to wiąże się z pojawieniem się nowych mechanizmów medialnych oraz wzmocnieniem obecności stereotypu niezasłużonej sławy w dyskursie publicznym $^{24}$. Usiłując dodać do dyskusji swój wkład, Fawcett odróżnia celebrytyzm od innych rodzajów sławy: reputacji, którą definiuje w oparciu o medium słowa mówionego, czyli plotki, oraz od renown, czyli chwały bądź sławy zasłużonej, przynależnej ludziom wielkim (co ciekawe, już niezależnej od rodzaju medium). Celebrity, rodzaj sławy, którego pojawienie się Autorka datuje na koniec XVII w., ma opierać się nie o wielkie czyny, tylko o to, kim są lub co reprezentują sławne postaci ${ }^{25}$. Taką próbę definicji trzeba uznać za szczególnie nieudaną. Istnieją liczne niejasności, jeśli chodzi o różnice definicyjne pomiędzy wcześniej wspomnianymi typami sławy (czy chwała nie może opierać się o słowo mówione? Czy ludzie wielcy nie mogą popełniać złych czynów?) i równie liczne, dobrze znane aspekty sławy, które pozostają zignorowane w takiej definicji celebrytyzmu (jak

${ }^{20}$ Warto sięgnąć po przegląd studiów nad sławą wieku XVIII - C. Wanko, Celebrity Studies in the Long Eighteenth Century. An Interdisciplinary Overview, „Literature Compass” 8, 2011, 6, s. 351-362.

${ }^{21}$ L. Engel, Stage Beauties. Actresses and Celebrity Culture in the Long Eighteenth Century, „Literature Compass” 13, 2016, 2, s. 749-50.

22 C. Wanko, Celebrity Studies, s. 351-355.

23 Świetnie opisane w pracy Toma Mole'a, Byron's Romantic Celebrity. Industrial Culture and the Hermeneutic of Intimacy, New York 2007. Patrz też: O. Driessens, Celebrity Capital. Redefining Celebrity Using Field Theory, „Theory and Society” 2013, 42, s. 543-560.

${ }^{24}$ S. Morgan, Celebrity. Academic „Pseudo-event” or a Useful Concept for Historians?, „Cultural and Social History” 8, 2011, 1, s. 95-114.

${ }^{25}$ J. Fawcett, op. cit., s. 8-9. 
choćby właśnie problem mediów). Kryterium reprezentacji jako wyróżnik celebrytyzmu jest nie do zaakceptowania co najmniej od czasu wydania głośnych prac socjologicznych na temat sławy, dzięki którym wiemy, że każdy jej rodzaj wiąże się z tym, kim jest lub co reprezentuje dana postać ${ }^{26}$. Jasne jest jednak, że ambicje Fawcett leżały poza społecznymi wnioskami, co tłumaczy jej ignorancję wobec ostatnich piętnastu lat socjologicznych dyskusji na ten temat. Społeczne uwarunkowania pojawienia się centralnego zjawiska sprowadzone zostały w książce do dwóch akapitów streszczenia bardziej dojrzałych przemyśleń, przede wszystkim tych Stelli Tillyard. Fawcett nie pozostawia wątpliwości, że jej celem jest eksploracja źródeł zgodnie z linią wytyczoną przez autorytety w jej dziedzinie.

\section{Celebryta jako efekt przemian historycznych}

W tym, jak i w wielu innych aspektach, praca Antoine'a Liltiego zrywa z dominującym nurtem. Lilti, do niedawna redaktor czasopisma „Annales” znanego z osiągnięć w stosowaniu podejścia interdyscyplinarnego, próbuje połączyć perspektywę historyczną i socjologiczną oraz wprowadzić temat celebrytyzmu do głównego nurtu historiografii. Przy tej okazji zaznaczyć należy, że jego książka pt. The Invention of Celebrity została opublikowana po raz pierwszy we Francji w roku 2014 jako Figures publiques. L'invention de la célébrité (1750-1850)27. Jednakże, publikacja angielskiego tłumaczenia tej pracy w 2017 r. jest wydarzeniem być może jeszcze istotniejszym od oryginalnego wydania, ponieważ przenosi ona głos Liltiego do debaty w języku angielskim, gdzie dochodzi do rozstrzygnięć o nieporównywalnie większym wpływie na kształt dziedziny, ze sfery francuskojęzycznej, gdzie debata zaczyna dopiero raczkować.

Lilti rozpoczął swoją pracę od postawienia pytań fundamentalnych, często pomijanych przez historyków celebrytyzmu. Twierdził on, że zachodnia kultura celebrycka nie została wynaleziona w wieku XX. Poszukiwanie źródeł zjawiska przywodzi Liltiego do epoki, którą Reinhart Koselleck określił jako „czas siodła” - okresu lat 1750-1850, który konwencja każe wiązać z narodzinami nowoczesnego (industrialnego) społeczeństwa. Opierając się na przykładach z Francji, ale również z Wielkiej Brytanii, Niemiec i północnej Ameryki, Autor dokonuje szerokiej syntezy naszej wiedzy o osiemnastowiecznej sławie, jednocześnie prowadząc swój wywód tematycznie i chronologicznie, stawiając celne pytania na temat społecznych przyczyn pojawienia się celebrytów. The Invention of Celebrity docenia znaczenie teatru, swoistego laboratorium zachowań zbiorowych, w którym wykiełkowało wiele mechanizmów potem przeniesionych do sfery publicznej, ale widzi tę rolę w szerszym kontekście rodzącego się przemysłu rozrywkowego, zbierającego tłumy wokół wystąpień sławnych tancerzy, aktorek,

${ }^{26} \mathrm{~Np}$. G. Turner, Understanding Celebrity, London 2004.

27 A. Lilti, Figures publiques. L'invention de la célébrité (1750-1850), Paris 2014. 
a nawet kastratów-falsecistów. Zbyt długi rozdział poświęcony jest ulubieńcowi Liltiego, Jeanowi-Jacques'owi Rousseau, który za życia stał się mistrzem manipulacji wizerunkiem, dzieląc się intymnymi przeżyciami z publicznością, a momentami panicznie jej unikając. Autor dostrzega też zwrot w zbiorowych oczekiwaniach wobec warstwy panującej. Wiek XVIII był okresem, w którym nadludzki autorytet władcy stracił na znaczeniu; ważne najpierw w życiu dworskim, a potem publicznym, stały się jego osobowość i prywatne odczucia. Postaci reprezentacyjne, jak twierdzi Lilti, zmieniły się w postaci publiczne.

Chociaż historyczny materiał i plejada ikonicznych postaci - Wolter, Franklin, Lafayette, Waszyngton, Robespierre, Bonaparte, Liszt - stanowi oś książki, Liltiemu udaje się również odpowiadać na ważne pytania teoretyczne. Często dzieje się to wbrew starszym teoriom: tym budowanym przez socjologów, którzy uważają celebrytyzm za zjawisko wyłącznie dwudziestowieczne; wbrew Jürgenowi Habermasowi, który widzi w racjonalności centralne pojęcie oświecenia; w końcu, wbrew podejściu typowemu dla historyków, którzy niechętnie sięgają po generalizacje. Lilti wskazuje na koncept publicity (fr. publicité), stan „uświadomienia sobie faktu i czerpania przyjemności wynikającej z tego, że jest się zainteresowanym tą samą rzeczą, co sobie współcześni”"28. Habermas podkreślał, że sfera publiczna pozostawała pod wpływem działania „komunikatywnego rozumu" i jako taka była ściśle racjonalna. Pojęcie publicity miało umożliwiać lepszy opis publicznego dyskursu w wieku XVIII, ponieważ mogło zawrzeć w sobie emocjonalność i irracjonalność prowadzenia społecznej rozmowy. Celebrytyzm w opinii Autora nieodłącznie powiązany jest z jedną taką emocją - ciekawością. Co interesujące, Lilti również oddziela go od reputacji i chwały, jednak znajdując nieco bardziej adekwatne definicje obydwu terminów niż Fawcett. Reputacja to stosunek grupy do każdego z jej członków. Chwała to pośmiertny mechanizm gloryfikacji wielkich ludzi uruchamiany przez „potomnych, instytucje kulturowe i ludzi dobrego smaku”29. Z kolei celebrytyzm stanowi oksymoroniczny konstrukt łączący rosnącą mediatyzację, czyli zwiększenie roli środków masowego przekazu w życiu codziennym (w XVIII w. rozrost przemysłu druku i prasy), oraz ,ideał bezpośredniego kontaktu pomiędzy twórcą [sztuki] i publicznością"30.

Przełomowość pracy Liltiego polega przede wszystkim na przesunięciu centrum dyskusji z teatru na bardziej abstrakcyjną problematykę społeczno-kulturową, czego konsekwencją jest otwarcie drogi do badań sławy dla historyków kultury niespecjalizujących się w tematyce teatru. Oczywiście, nie jest to pierwsza tego rodzaju praca. Teorię społeczną i refleksję historyczną łączono już na

28 „The public is defined [--] by sharing the same curiosity and the same beliefs, by being interested in the same things at the same time and by being aware of this simultaneity", A. Lilti, The Invention of Celebrity, s. 9-10.

29 „Posterity, cultural institutions and people of good taste”, ibidem, s. 5-7.

30 "The ideal of an immediate meeting between the creator and the public", ibidem, s. 218-219. 
gruncie socjologii celebrytyzmu; historyczne prace Stevena Gundle'a, Franka Inglisa i Toma Mole'a również zwracały uwagę na szeroki kontekst badanych wydarzeń ${ }^{31}$. Jednakże, mnogość omówionych przypadków, ich czasowy rozstrzał oraz dystans wobec prezentystycznej wizji centralnego zjawiska sprawiają, że Lilti nabiera szczególnej mocy przekonywania.

\section{Celebryta interdyscyplinarnie}

Podczas gdy książka Fawcett jest dobrym przykładem feministyczno-teatralnego punktu widzenia na historyczny celebrytyzm, a praca Liltiego zawiera socjologiczno-historyczną propozycję, wydana w 2018 r. Intimacy and Celebrity przedstawia wiele perspektyw. Jest to zbiór esejów pod redakcją dwojga brytyjskich badaczy, który powstał jako m.in. konsekwencja panelu „Celebrity and Intimacy" na kongresie Brytyjskiego Towarzystwa Badań nad Wiekiem Osiemnastym w 2017 r. Sam fakt obecności tematu celebrytyzmu na jednym z najważniejszych wydarzeń naukowych związanych z historiografią oświecenia znamionuje przemianę postaw wobec tej dziedziny wśród brytyjskich historyków. Omawiając tom, warto więc zwrócić uwagę, na ile prąd społeczno-kulturowej refleksji historycznej, którego rezultatem było tłumaczenie pracy Liltiego na angielski, przeniknął do historiografii celebrytyzmu.

Chociaż w Intimacy and Celebrity efekty tego transferu są widoczne, większość pracy utrzymana jest w znajomej konwencji. Eseje są tematycznie pogrupowane w cztery części. Pierwsza i najdłuższa z nich poświęcona jest znowu teatrowi, powracają też te same postaci celebrytów-aktorów - James Harriman-Smith omawia w niej te aspekty historii sławy, które towarzyszyły śmierci Davida Garricka ${ }^{32}$, a Elaine McGirr niemalże na wzór Fawcett opisuje „artefakt”, który wykorzystywał Colley Cibber, angielski aktor i poeta (tym razem część ciała - pierś) ${ }^{33}$. Victoria Joule, współredaktor tomu, kontynuuje wątek cielesności w twórczości Susanny Centlivre, „najwybitniejszej kobiety dramaturga w wieku XVIII"34, a Claudine van Hensbergen powraca do materii nieożywionej w swoim tekście dotyczącym osobistych przedmiotów osiemnastowiecznych gwiazd wystawianych po ich śmierci na aukcje ${ }^{35}$. Nie pozostaje bez znaczenia, że

${ }^{31}$ T. Mole, op. cit.; S. Gundle, Glamour. A History, Oxford 2008; F. Inglis, A Short History of Celebrity, Princeton 2010. Osobiście, poszedłbym jeszcze krok dalej. Patrz: A. Wesołowski, Beyond Celebrity History. Towards the Consolidation of Fame Studies, „Celebrity Studies”, www.tandfonline.com/doi/full/10.1080/19392397.2018.1527705 (dostęp: 25 VI 2019).

32 J. Harriman-Smith, Garrick, Dying, w: Intimacy and Celebrity, s. 83-110.

33 E. McGirr, Nell Gwyn's Breasts and Colley Cibber's Shirts. Celebrity Actors and Their Famous „Parts”, w: ibidem, s. 13-34.

34 V. Joule, „Peeping” and Public Intimacy in Susanna Centrlivre's The Busy Body (1709), w: ibidem, s. 59-82.

35 C. van Hensbergen, Anne Oldfield's Domestic Interiors. Auctions, Material Culture and Celebrity, w: ibidem, s. 35-58. 
cielesność jest tematem, który stoi w centrum nowego celu teorii feministycznej proponowanej względnie niedawno przez Judith Butler ${ }^{36}$. Ponieważ w podtytule tomu pojawia się pojęcie kultury literackiej, nie powinno dziwić, że część pracy dotyczy autorów prac literackich. Nicola Parsons, Clare Brant i Ruth Scobie eksplorują tę stronę celebrytyzmu, przy czym docenić należy, że zainteresowanie Autorek z książek coraz bardziej przenosi się w stronę prasy, zaskakująco niedopracowanego tematu, biorąc pod uwagę specyfikę opisywanego zjawiska ${ }^{37}$.

Bez wątpienia cennym wkładem są eseje umieszczone w części dotyczącej polityki, sfery niemalże nieobecnej w historiografii celebrytyzmu. Postać doktora Sacheverella, opisywana przez Briana Cowana ${ }^{38}$, anglikańskiego kaznodziei, którego proces o zdradę stanu uczynił go „najsłynniejszą osobą za rządów królowej Anny", jest jeszcze bardziej interesująca. Jego droga do sławy wiodła nie tylko poprzez politykę, ale również przez prześladowania religijne, których doświadczył. Tekst Rebecki Tierney-Hynes ${ }^{39}$, chociaż powracający do figury pisarza (Fieldinga), również wyróżnia się oryginalnością; poświęcony jest bowiem koncepcji publicznej emocji i zawiera wiele uwag bliższych historii intelektualnej niż bardziej typowemu dla dziedziny podejściu literaturoznawczemu. Natomiast Emrys D. Jones, drugi współredaktor tomu, łączy wątki wspomniane przez Fawcett i ambicje Liltiego w znakomitym eseju poświęconym tzw. publicznej intymności. Jones wskazuje na polityczny mechanizm używany przez ludzi, których uważa się za wielkich, dzięki któremu sygnalizują oni to, co łączy ich z szarym człowiekiem za pomocą strategicznego ujawniania swojej prywatnej twarzy publicznie. Autor wyraźnie zaznacza, jak istotne jest przesunięcie centrum uwagi z teatru na sferę polityczną oraz wskazuje na możliwość opisywania celebrytów za pomocą sposobu, w jaki publika angażuje się w konstrukcję i dekonstrukcję ich wizerunku ${ }^{40}$. Zbiór kończy się częścią czwartą, czyli artykułem George'a Rousseau dotyczącym intymności i niesławy (notoriety) oraz krótkim epilogiem autorstwa kolejnego autorytetu w dziedzinie, Laury Engel, powracającym do tematu cielesności ${ }^{41}$.

Intimacy and Celebrity z jednej strony rozwija studia nad sławą jako specjalizację historii teatru, a $\mathrm{z}$ drugiej oferuje nowe podejścia, przy czym tekst

${ }^{36}$ J. Butler, Bodies That Matter. On the Discursive Limits of Sex, New York 1993.

37 N. Parsons, ,The ARMS of Friendship”. John Dunton's Platonic Acquisitions, w: Intimacy and Celebrity, s. 189-210; C. Brant, „I Make a Very Shining Figure”. Lady Mary Wortley Montagu and the Intimate Publicity of Autorship, w: ibidem, s. 211-232; R. Scobie, Foote, Fox, and the Mysterious Mrs Grieve. Print Celebrity and Imposture, w: ibidem, s. 233-258.

38 B. Cowan, Doctor Sacheverell and the Politics of Celebrity in Post-Revolutionary Britain, w: ibidem, s. 111-138.

${ }^{39}$ R. Tierney-Hynes, Farcical Politics. Fielding's Public Emotion, w: ibidem, s. 139-164.

${ }^{40}$ E. Jones, „A Man in Love”. Intimacy and Political Celebrity in the Early Eighteenth Century, w: ibidem, s. 165-188.

${ }^{41}$ G. Rousseau, Notoriety's Public Interiors. Mid-Georgians Combining Celebrity and Intimacy, with an Appendix on the Rotunda at Ranelagh, w: ibidem, s. 259-292; L. Engel, Body Double - Katherine Hepburn at Madame Tussauds, w: ibidem, s. 293-298. 
Jonesa w oryginalny sposób łączy obydwa: pokazuje alternatywę, jednocześnie doceniając bogactwo starszej tradycji. Tom zbiorczy dobrze oddaje najnowsze trendy badawcze. Celebrity history poszerza się zarówno o nowe typy celebrytów (gwiazdy polityki czy religii), jak i nowatorskie metody historycznego badania sławy. Choć większość prac poświęconych tematowi wciąż odtwarza perspektywę jednostkowych celebrytów i problemów ich autokreacji lub osobistych przeżyć związanych ze sławą, rosnąca liczba badań opisuje pośredników w przekazie wizerunku albo, za postulatem Graeme'a Turnera ${ }^{42}$, przedstawia działanie przemysłu celebryckiego (celebrity industry). Jak dowodzi przykład Intimacy and Celebrity, historia celebrytów jest wciąż uzależniona od historii teatru i teorii feministycznej, czasami do tego stopnia, że odpowiada na niewielkie przesunięcia akcentów proponowane przez feministki bardziej niż np. na piśmiennictwo socjologiczne dotyczące celebrytyzmu.

\section{Wnioski}

Trzy przedstawione w ten sposób prace, być może ze względu na swoje różnice, zawierają w sobie ślad przekształceń omawianej dziedziny. Przewaga ujęć literaturoznawczych i z zakresu historii teatru ściera się w tym momencie z coraz bardziej popularnymi propozycjami historii społecznej, a miejscami - socjologii historycznej. Te dwie metody, oczywiście, w żaden sposób się nie wykluczają. $\mathrm{Na}$ etapie wniosków nie sposób też nie docenić punktów wspólnych dla każdej z prac. Czymś, co łączy wszystkie, jest perspektywa skupiająca się na historii prywatności i intymności. Taki punkt widzenia podyktowany został chęcią uchwycenia historycznie znaczącej różnicy pomiędzy celebrytyzmem i innymi rodzajami sławy. Autorzy przyjmują strategię podkreślenia znaczenia, jakiego podczas wieku XVIII nabierać zaczęła intymność znanych osób jako przedmiot zainteresowania w życiu publicznym. Chociaż plotka zawsze żywiła się tajemnicą, w tym okresie fascynacje prywatnymi detalami z życia znanych osobowości urosły do rangi fenomenu: rosnąca rola empatii i współodczuwania sprawiła, że gwiazdy wydawały się bliższe szaremu człowiekowi, a wokół nich pojawiły się nowe formy zbiorowego zachowania, jak fandom, i nowe mechanizmy rynkowe, np. utowarowienie wizerunków sławnych osób. Ta reorientacja sławy w stronę rynku i codzienności jest punktem wyjścia dla dyskusji, jaką podejmują Autorzy.

Imponująca wydaje się liczba możliwych podejść i wątków do rozwinięcia. Jest ona poniekąd wyrazem różnorodności metodologicznej, w jaką wyposażeni są współcześni historycy, ale z drugiej strony to rezultat powszechności problemu sławy, która zakrada się do najmniejszych elementów życia zbiorowego (a czasem i prywatnego). Historia, jak dostrzegał Leo Braudy, ma swój własny problem ze sławą, ponieważ sam aspekt relacjonowania wydarzeń ma wiele wspólnego z popularnością danej tematyki - „wszystko, co zachowało

\footnotetext{
${ }^{42}$ G. Turner, Approaching Celebrity Studies, „Celebrity Studies” 1, 2010, 1, s. 11-20.
} 
się z przeszłości jest w pewnym sensie przesłaniem, które przedłuża czyjąś sławę"43. Ten zbiór problemów nie powinien nas jednak odwodzić od badania celebrytyzmu i innych rodzajów sławy. Im bardziej zagadnienie wydaje się niewyjaśnialne, tym bardziej jest warte wyjaśnienia. To przesłanie powinno towarzyszyć każdemu, kto podejmie zadanie przeniesienia historycznej refleksji nad sławą na grunt nauki polskiej.

\section{Streszczenie}

Czy sława to wartościowy przedmiot badań historycznych? Czy celebryci na zawsze pozostaną w domenie specjalistów od marketingu? Historiografia sławy i celebrytyzmu, żywa w anglosaskim dyskursie akademickim, odpowiada na drugie pytanie stanowczym: nie! Poniższy tekst jest zbiorczą recenzją trzech prac dotykających wspomnianej problematyki, jakie ukazały się w niedawnym czasie: J. Fawcett, Spectacular Disappearances. Celebrity and Privacy, 1696-1801, Ann Arbor 2016, A. Lilti, The Invention of Celebrity, 1750-1850, Cambridge 2017 oraz Intimacy and Celebrity in Eighteenth-Century Literary Culture, red. E. Jones, V. Joule, Cham 2018. Dobór prac dyktowany był próbą reprezentacji różnorodności badań w zakresie historii celebrytyzmu z typowym dla dziedziny skupieniem na wieku XVIII. Wybrano książki badające sławę z dominującej perspektywy łączącej teorię feministyczną, historię teatru i literaturoznawstwo, z punktu widzenia historyczno-społecznego oraz zbiór tekstów będący rezultatem zjazdu historyków brytyjskich w 2017 r.

Recenzji towarzyszy również próba oceny, na ile dane prace reprezentują najsilniejsze prądy w dziedzinie, dzięki czemu artykuł przybliża polskiemu środowisku stan badań nietypowej dyscypliny historycznej. Niełatwa problematyka nie podlega pełnemu opisowi. Tekst stanowi raczej zarys metod podejścia do tematu w historiografii brytyjskiej, gdzie wybija się on na jeden z silniejszych prądów łączących dotychczasowe odkrycia studiów nad oświeceniem z nowymi perspektywami przychodzącymi do badań historycznych z nauk społecznych. W obliczu tempa wzrostu nowej dziedziny i jej historycznego aspektu, istotne jest, żeby polski historyk potrafił się do niej ustosunkować oraz, być może, żeby znalazła ona przełożenie na gruncie historii Rzeczypospolitej.

\section{Three Stories about Celebrities}

Is fame a valuable problem for historiography, or will it always remain in the domain of marketing experts? The English celebrity history, well-developed in the West, would react with a fervent refusal to any attempts at considering fame being thought ahistorical. This article is a review of three current works pertaining to the problem: Julia H. Fawcett's Spectacular Disappearances. Celebrity and Privacy, 1696-1801

43 „Everything preserved for us from the past can in some sense be considered a message that perpetuates someone's fame”, L. Braudy, op. cit., s. vii. 
(Ann Arbor, 2016); Antoine Lilti's The Invention of Celebrity, 1750-1850 (Cambridge, 2017); and Intimacy and Celebrity in Eighteenth-Century Literary Culture, edited by Emrys D. Jones, and Victoria Joule (Cham, 2018). The books were selected as to represent a wide range of research conducted within the celebrity history field. They examine celebrity and its history from the dominant perspective, combining the feminist theory, theatre history, and literary studies, the social history perspective stemming from France, and an interdisciplinary one, resultant from the ISECS 2017 Congress.

Additionally, the article attempts to determine whether a Polish historian can use its contents as fair examples of the current trends in celebrity history. The goal is to familiarise a Polish historian with the so far unexplored field of study.

As the complex issues evade an easy summary, the text is more an outline of methods and approaches present within the British historiography, where celebrity history is one of the most developed trends of the day, combining the studies of Enlightenment with new perspectives of the social sciences. In the face of its rapid development, it is important that the Polish historian was able to partake in the conversation and, probably, to implant it home.

Translated by Grażyna Waluga

\section{Bibliografia}

Adorno Theodore, Horkheimer Max, Dialektyka oświecenia, Wydawnictwo Instytutu Filozofii i Socjologii PAN, Warszawa 1994.

Bauman Zygmunt, Liquid Life, Polity, Cambridge 2005.

Bennett James, Historicising Celebrity Studies, „Celebrity Studies” 1, 2010, 3, s. 358-359.

Boorstin Daniel, The Image or What Happened to the American Dream, Atheneum, New York 1962.

Braudy Loe, The Frenzy of Renown. Fame and its History, Oxford University Press, Oxford 1986.

Butler Judith, Gender Trouble. Feminism and the Subversion of Identity, Routledge, New York 1991.

Butler Judith, Bodies That Matter. On the Discursive Limits of Sex, Routledge, New York 1993.

Driessens Olivier, Celebrity Capital. Redefining Celebrity Using Field Theory, „Theory and Society" 2013, 42, s. 543-560.

Engel Laura, Stage Beauties. Actresses and Celebrity Culture in the Long Eighteenth Century, „Literature Compass” 13, 2016, 2, s. 749-59.

Fawcett Julia, Spectacular Disappearances. Celebrity and Privacy, 1696-1801, University of Michigan Press, Ann Arbor 2016.

Gundle Stephen, Glamour. A History, Oxford University Press, Oxford 2008.

Inglis Fred, A Short History of Celebrity, Princeton University Press, Princeton 2010. Intimacy and Celebrity in Eighteenth-Century Literary Culture, red. Emrys D. Jones, Victoria Joule, Palgrave Macmillan, Cham 2018.

Lilti Antoine, The Invention of Celebrity, 1750-1850, Polity, Cambridge 2017 (wyd. oryg. Figures publiques. L'invention de la célébrité (1750-1850), Fayard, Paris 2014). 
Linebaugh Peter, London Hanged. Crime and Civil Society in the Eighteenth Century, Cambridge University Press, Cambridge 1992.

McKenzie Andrea, The Real MacHeath, Social Satire, Appropriation, and 18th-century Criminal Biography, „Huntington Library Quarterly” 69, 2006, 4, s. 581-605.

Micińska Magdalena, Między Królem Duchem a mieszczaninem. Obraz bohatera narodowego w piśmiennictwie polskim przełomu XIX i XX w. (1890-1914), Leopoldinum, Wrocław 1995.

Mole Tom, Byron's Romantic Celebrity. Industrial Culture and the Hermeneutic of Intimacy, Palgrave Macmillan, New York 2007.

Molęda-Zdziech Małgorzata, Czas celebrytów. Mediatyzacja życia publicznego, Difin, Warszawa 2013.

Morgan Simon, Historicising Celebrity, „Celebrity Studies” 1, 2010, 3, s. 366-368.

Morgan Simon, Celebrity. Academic „Pseudo-event” or a Useful Concept for Historians?, „Cultural and Social History” 8, 2011, 1, s. 95-114.

Morin Edgar, Les stars, Seuil, Paris 1972.

Nussbaum Felicity, Rival Queens. Actresses, Performance, and the Eighteenth-century British Theater, Pennsylvania University Press, Philadelphia 2010.

Ossowska Maria, Ethos rycerski i jego odmiany, PWN, Warszawa 1986.

Rojek Chris, Celebrity, Reaktion Books, London 2001.

Straub Kristina, Sexual Suspects. Eighteenth-century Players and Sexual Ideology, Princeton University Press, Princeton 1992.

Theatre and Celebrity in Britain 1660-2000, red. Mary Luckhurst, Jane Moody, Palgrave Macmillan, Basingstoke 2005.

Tillyard Stella, „Paths of glory”. Fame and the Public in Eighteenth-century London, w: Joshua Reynolds. The Creation of Celebrity, red. Martin Postle, Tate Publishing, London 2005, s. 61-69.

Turner Graeme, Understanding Celebrity, SAGE, London 2004.

Turner Graeme, Approaching Celebrity Studies, „Celebrity Studies” 1, 2010, 1, s. 11-20. Wanko Cheryl, Roles of Authority. Thespian Biography in Eighteenth-century England, Texas Tech University Press, Lubbock 2003.

Wanko Cheryl, Celebrity Studies in the Long Eighteenth Century. An Interdisciplinary Overview, „Literature Compass” 8, 2011, 6, s. 351-362.

Wesołowski Adrian, Beyond Celebrity History. Towards the Consolidation of Fame Studies, „Celebrity Studies”, www.tandfonline.com/doi/full/10.1080/19392397.2018.15 27705 (dostęp: 25 VI 2019).

Wesołowski Adrian, Nieśmiertelny i dobroczynny. Historyczne badanie genezy i charakteru sławy Stanisława Staszica, KH 125, 2018, 1, s. 29-63.

Biogram: Adrian Wesołowski, doktorant na Wydziale Historycznym Uniwersytetu Warszawskiego oraz w Instytucie Antropologii Społecznej Towarzystwa Maxa Plancka w Halle an der Saale, zainteresowania naukowe: lata 1750-1850, stosowanie metod nauk społecznych w badaniach historycznych, dzieje sławy, historia filantropii i dobroczynności; kontakt: wesolowskiad@gmail.com. 